\title{
Twenty years of the Centre for Evidence-based Dentistry
}

\section{Derek Richards \\ Editor, Evidence-based Dentistry}

This year marks 20 years since the establishment of the Centre for Evidence-based Dentistry. The decision to establish a Centre was taken following a workshop held at Templeton College, Oxford in December 1994 and formally established with the holding of an inaugural Board meeting held in the offices of the Postgraduate Deanery in Oxford. At that meeting the core aim of the centre was defined:

\section{'to promote the teaching, learning, practice and evaluation of Evidence-based Dentistry'}

Since that time the Centre has delivered or participated in more than 100 workshops across the UK and a range of other countries including Brazil, Canada, India, New Zealand, Norway, Portugal, Saudi Arabia and the USA. The Centre has also participated in the Oxford MSc. in Evidence-Based Health Care Programme and Critical Appraisal Skills Programme (CASP). Later this year the Centre is expecting to deliver workshops in Egypt and Pakistan.

Soon after the establishment of the Centre a website was created to provide a resource for members of the dental team with an interest in finding out more about EBD. That website was initially hosted at the Institute of Health Sciences in Oxford but later moved to its own domain (www.cebd.org) and it is currently in its fourth design iteration (Fig. 1)

In addition to establishing an Evidence-based Centre for Dentistry one of the other key tasks that was articulated at the Templeton workshop was the need to develop an evidence-based dentistry journal. This led to discussions with potential publishing partners including the British Dental Journal, and the subsequent launch of the Evidence-based Dentistry Journal initially as a supplement of the BDJ (Fig. 2). In the year 2000 the journal moved to a quarterly publication schedule and became a stand-alone journal, achieving a Medline listing in 2004.

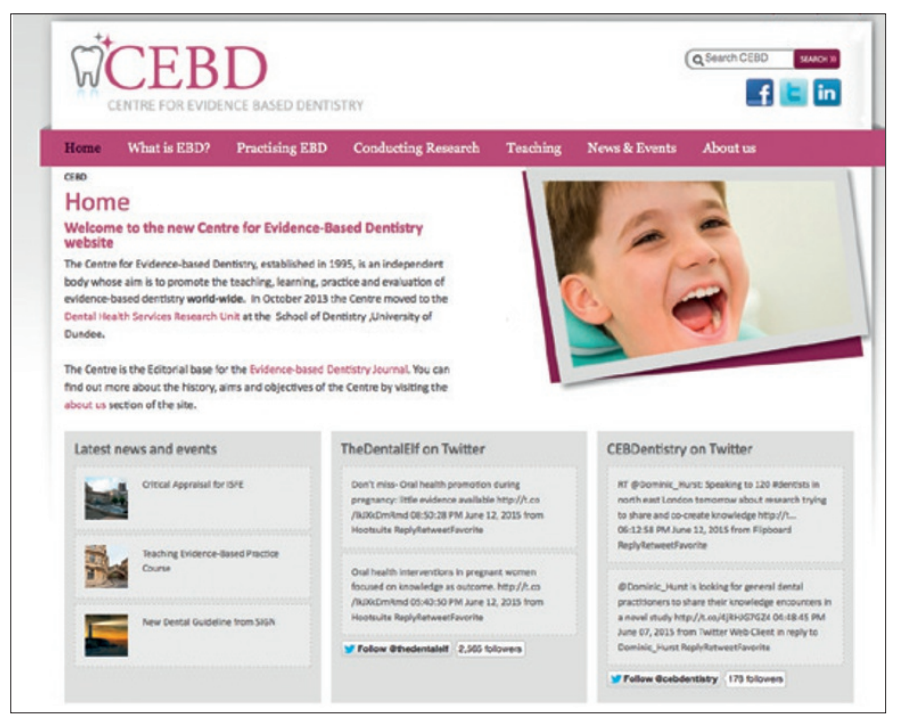

Figure 1: Current Centre for Evidence-based Dentistry website home page
The Centre's latest venture to help disseminate evidence and encourage discussion is the Dental Elf (www.thedentalelf.net). This is a blog site that aims to help dental colleagues keep up to date with the latest evidence. The site was launched in June 2011 (Fig. 3) and is one of a number of health and social care sites that includes a Child Elf, Commissioning Elf, Diabetes Elf, Education Elf, Learning Disabilities Elf, Lifestyle Elf, Mental Elf, Musculoskeletal Elf, Social

Care Elf and Stroke Elf; together the elves constitute the National Elf Service (http://www.nationalelfservice.net/).

In addition to these achievements there have been contributions to a range of evidence-based guidelines and publications over the years and we have seen the inclusion of evidence-based dentistry into teaching guidance for dental students both here and in the USA. Other Evidence-based Dental Centres have been established in America, Egypt and India to my knowledge, and no doubt there are others. These accomplishments have been hard won over the years but the Centre has yet to establish a profile approaching that of the Centre for Evidence-based Medicine (www.cebm.net). The recent move to Dundee and formal academic links within the Dental School may help in this regard but there is still much to do both about the quality of the evidence available for the practice of dentistry and to improve its integration into everyday practice.

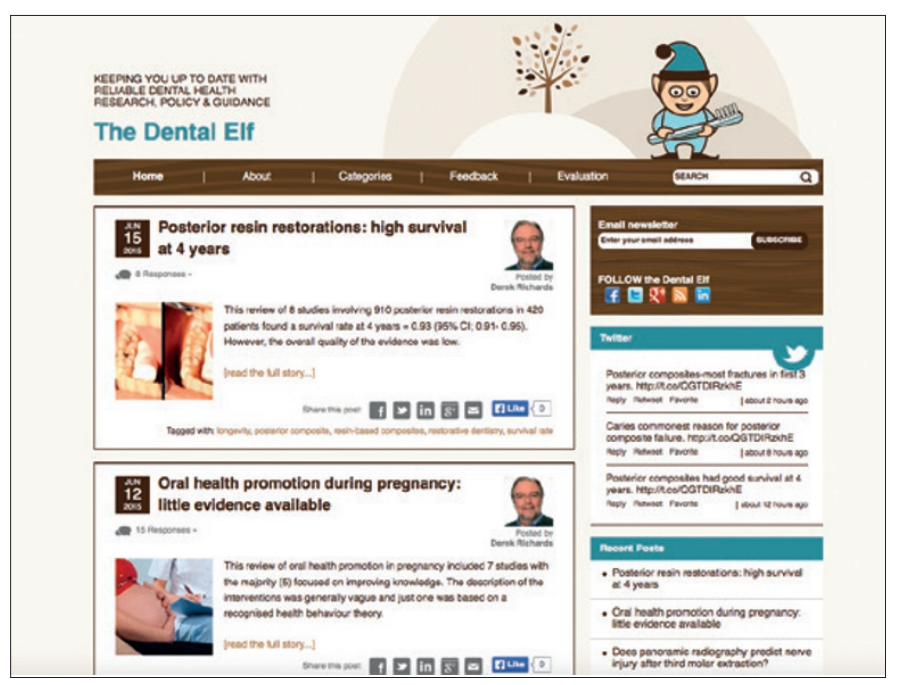

Figure 3. The Dental Elf home page

Evidence-Based Dentistry (2015) 16, 34. doi:10.1038/sj.ebd.6401108 